\title{
ASUHAN KEBIDANAN AKUPRESSURE SP6 DAN LI4 UNTUK MENGURANGI TINGKAT NYERI PADA PERSALINAN FASE AKTIF DI KLINIK PRATAMA AR-RABIH KOTA PEKANBARU TAHUN 2020
}

\author{
Nelly Karlinah, Melti Marzellina \\ STIKes Hangtuah Pekanbaru \\ nellykarlinah87@gmail.com \\ meltimarzellina399@gmail.com
}

\begin{abstract}
Pain causes stress because stress can release catecholamines which result in reduced blood flow to the uterus so that the uterus is deprived of oxygen. Acupressure can stimulate the release of endorphins in the blood so that labor pain can be controlled and also stimulates the release of oxytocin from the pituitary gland which stimulates uterine contractions. Of the 10 women who gave birth to overcome pain during labor, the midwife only taught them to relax, do breathing exercises, turn on music. This was less effective for mothers who gave birth and mothers who gave birth still experienced levels of pain. The goal is to carry out midwifery care for laboring mothers to reduce labor pain by using acupressure at points Sp6 and Li4. The method used is a case study, which was carried out at the Ar-rabih pratama clinic on September 16, 2020. The criteria for giving birth are full-term gestation, age 20-35 years, should not be done at 6 months of gestation. miscarriage, not done emotionally (angry, scared, too happy and sad), not too hungry and full, massage aids are not sharp and clean. The suggestion for midwives is that it is hoped that health service providers who are running a practice can provide acupressure massage and it is also hoped that in clinics for services to maternity mothers to be able to provide leaflets on acupressure massage.

Keywords: Childbirth, Pain, Acupressure, Ar-rabih Primary Clinic
\end{abstract}

\begin{abstract}
ABSTRAK
Nyeri mengakibatkan stress karena stress dapat melepaskan katekolamin yang mengakibatkan berkurangnya aliran darah ke uterus sehingga uterus kekurangan oksigen. Akupresure dapat merangsang pengeluaran endorphin dalam darah sehingga nyeri persalinan dapat terkontrol dan juga merangsang pelepasan oksitosin dari kelenjar hipofisis yang merangsang kontraksi rahim. Dari $10 \mathrm{ibu}$ bersalin mengatasi nyeri selama persalinan bidan hanya mengajarkan tetap rileks, latihan pernapasan, hidupkan music ini kurang efektif bagi ibu bersalin dan ibu bersalin masih mengalami tingkat nyeri. Tujuan yaitu melaksanakan asuhan kebidanan pada ibu bersalin untuk mengurangi rasa nyeri persalinan dengan menggunakan akupressure pada titik Sp6 dan Li4. Metode yang digunakan adalah studi kasus, yang ini dilaksanakan di klinik pratama Ar-rabih pada tanggal 16 September 2020. Kriteria yang dilakukan pada ibu bersalin yaitu usia kehamilan cukup bulan, umur 20-35 tahun, tidak boleh dilakukan pada usia kehamilan 6 bulan akan mengakibatkan keguguran, tidak dilakukan dalam emosional (marah,takut,terlalu gembira dan sedih), tidak terlalu lapar dan kenyang, alat bantu pijat tidak tajam dan bersih. Saran untuk bidan adalah di harapkan kepada penyedia layanan kesehatan yang sedang menjalankan praktik untuk bisa menyediakan pijat akupressure dan juga diharapkan pada klinik terhadap pelayanan pada ibu bersalin untuk dapat menyediakan leaflet tentang pijat akupressure.
\end{abstract}

Kata Kunci : Persalinan, Nyeri, Akupressure, Klinik Pratama Ar-rabih 


\section{PENDAHULUAN}

Persalinan adalah proses pengeluaran janin yang cukup bulan (37-42 minggu) yang hidup diluar kandungan melalui jalan lahir di susul dengan pengeluaran plasenta dan selaput janin yang bersifat spontan, dengan presentasi belakang kepala yang berlangsung 18 jam tanpa alat bantu atau kekuatan sendiri tidak ada penyulit atau komplikasi baik ibu maupun bayinya (Mutmainnah, A. U., Jihan, H. H., \& Llyod, S. S. (2017).

Pada kala 1 persalinan, kontraksi rahim menyebabkan dilatasi serviks dan iskemia rahim (penurunan aliran darah sehingga oksigen lokal dapat mengalami deficit akibat kontraksi arteri miometrium. (Fauziah, 2015).

Adapun peran bidan dalam mengurangi nyeri selama persalinan dengan cara mandi air hangat, kompres hangat atau dingin, terus bergerak seperti jalan-jalan atau berjongkok, manjakan diri dengan sentuhan atau pijatan lembut, latihan pernapasan, memanfaatkan visualisasi dan audio seperti melihat wajah pasangan dan mendengarkan musik (Sari \& Rimandini, 2014).

Akupresur menggunakan tangan untuk memijat bagian-bagian tubuh tertentu. Titik-titik yang berhubungan dengan persalinan adalah SP6 dan LI4 dimana titik ini dapat merangsang pelepasan hormon oksitosin untuk induksi persalinan dan pengelolaan nyeri selama persalinan. Penekanan acupoint SP6 memiliki pengaruh kuat terhadap organ refroduksi memperlancar proses persalinan dengan membantu di latasi servik sedangkan acupoint LI4 memiliki efek mengurangi rasa sakit dan merangsang kontraksi uterus (Lee et, 2001) dalam (Sujiyatini \& Djanah, 2016).

Dari hasil penelitian yang dilakukan oleh (Angelia \& Lokawati), responden yang mengalami nyeri sangat berat sejumlah $13,3 \%$, hal tersebut dikarenakan bertambahnya pembukaan serviks dan kontraksi yang semakin kuat hal ini meyebabkan nyeri semakin berat dan tidak dapat di kontrol. Setelah diberikan akupresure pada 15 responden dapat diambil bahwa 4 responden $(26,6)$ mengalami nyeri sedang, 12 responden $(73,3 \%)$ mengalami nyeri berat, dan tidak ada responden yang mengalami nyeri sangat berat. Hasil penelitian tersebut bahwa akupresure dapat merangsang pengeluaran endorphin dalam darah sehingga nyeri persalinan dapat terkontrol dan akupresure juga bisa merangsang pelepasan oksitosin dari kelenjar hipofisis dapat merangsang kontraksi rahim.

\section{METODE}

Metode yang penulis gunakan yaitu Asuhan Kebidanan Akupresur Sp6 dan 
Li4 Untuk Mengurangi Tingkat Nyeri Pada Persalinan Fase Aktif. Asuhan yang diberikan kepada ibu bersalin untuk mengurangi rasa nyeri tanpa menggunakan obat-obatan dengan teknik Akupressure Sp6 dan Li4 dan menggunakan skala wajah untuk melihat nyeri yang dirasakan ibu. Pada Ny.M umur 24 tahun G3P2A0, yang dilaksanakan di Klinik Pratama Ar-rabih pada tanggal 16 September 2020.

\section{HASIL}

\section{Kunjungan pada Ny. M}

\section{Hari/ Tanggal : Rabu/ 16 September 2020 Pukul : 11.00 wib}

\section{Data Subjektif}

Ibu mengatakan berusia 24 tahun, Ibu mengatakan bekerja sebagai ibu rumah tangga, Ibu mengatakan ini hamil yang ketiga,_Riwayat kehamilan sekarang : sehat,_Riwayat kesehatan ibu dan keluarga : tidak sedang menderita penyakit, Ibu mengatakan HPHT : 01-1219, Ibu mengatakan nyeri pinggang menjalar ke ari-ari, sejak pukul 02.00

\section{Data Objektif}

Keadaan umum ibu baik, kesadaran composmentis,TD:120/80 $\mathrm{mmHg}$, N:80x/i, R:20x/I, S:36, $7^{\circ} \mathrm{C}$, Berat Badan Sebelum Hamil:59 kg, Berat Badan Sekarang : $74 \mathrm{~kg}$, Tinggi Badan : $150 \mathrm{~cm}$,
Pemeriksaan abdomen : pada bagian bawah janin teraba bulat, keras dan melenting yaitu kepala janin, Kepala janin bersentuhan dengan PAP. Leopold IV : Divergen, TFU MC, Donald : $30 \mathrm{~cm}$, Denyut Jantung Janin : 140x/menit, Tafsiran Berat Janin : (30 -13) x $155=$ 2635 gram, His 3x dalam 10 menit frekuensinya 35 detik, VT : pembukaan 4 $\mathrm{cm}$, portio tipis, lunak, ketuban pecah berwarna jernih, presentasi kepala, Sebelum melakukan teknik akupressure menyatakan ibu berada dalam skala 5 memiliki nyeri skala sedang, setelah di lakukan teknik akupressure bahwa hasil yang di dapatkan cukup baik dapat mengurangi nyeri di pembukaan $4 \mathrm{~cm}$ ibu berada skala 4 . Karena pijatan ini bisa membuat ibu menjadi lebih nyaman dan bisa mengurangi rasa nyeri pada saat persalinan.

\section{$\underline{\text { Asesment }}$}

G3P2A0 usia kehamilan 38 minggu inpartu kala 1 fase aktif dengan KPD k/u ibu baik, janin hidup, tunggal, intrauterine, presentasi kepala, k/u janin baik.

\section{Plan}

Informasi, edukasi, dan terapi

1) Beritahu hasil pemeriksaan

2) Kebutuhan nutrisi 
3) Konseling mengurangi nyeri persalinan

4) Informed consent tentang teknik pijat akupressure

5) Pemberian teknik akupressure

6) Kemajuan persalinan

7) Kebutuhan selama inpartu

\section{Lembar implementasi}

Informasi dan Edukasi :

1. Memberitahu ibu hasil pemeriksaan bahwa keadaan ibu baik, TD : 120/80 $\mathrm{mmHg}, \mathrm{N}$ : 80x/menit, $\mathrm{R}$ : 20x/menit, $\mathrm{S}: 36,7^{\circ} \mathrm{C}$, VT : $4 \mathrm{~cm}$, ketuban (-), DJJ : 140x/i dan keadaan janin dalam batas normal.

2. Menganjurkan ibu untuk mendapatkan asupan makanan dan minuman selama persalinan, karena dapat memberi banyak energi dan mencegah dehidrasi. Dehidrasi dapat memperlambat kontraksi, menjadi tidak teratur dan kurang efektif.

3. Memberikan informed consent kepada ibu untuk melakukan teknik pijat akupressure dalam mengurangi rasa nyeri persalinan ibu. (ibu setuju untuk dilakukan teknik pijat akupressure)

4. Menjelaskan kepada ibu bahwa nyeri yang ibu rasakan sekarang adalah suatu hal yang fisiologis atau hal yang wajar terjadi pada ibu bersalin karena adanya kontraksi uterus, dilatasi dan penipisan serviks, serta penurunan janin selama persalinan. Beritahu ibu untuk melakukan teknik relaksasi pernapasan.

5. Menjelaskan kepada ibu selain teknik relaksasi pernapasan, melakukan teknik akupressure juga dapat mengurangi rasa nyeri. Karena teknik akupressure ini bisa mengurangi nyeri persalinan dan merangsang kontraksi pada saat persalinan.

6. Mengukur skala nyeri dengan menggunakan FRS (wajah) untuk menegtahui tingkatan rasa nyeri ibu, hasilnya ibu berada pada skala wajah.

7. Melakukan pijat akupressure kepada ibu untuk mengurangi nyeri persalinan dengan cara :

perhatikan kenyaman dan kenyamana pasien

lakukan penekanan pada titik SP6 (terletak pada pergelangan kaki)

lakukan penekanan dengan putaran sebanyak 30 kali searah jarum jam pada titik SP6 selama 15

8. Memberikan support kepada ibu agar tetap semangat untuk menjalani proses persalinannya. 
9. Memberitahukan kepada ibu bahwa nyeri merupakan fisiologi pada saat mau melahirkan bayi, karena kontraksi semakin kuat.

10. Menanyakan kepada ibu tentang nyeri yang dirasakannya setelah dilakukan teknik akupressure, ibu mengatakan nyeri nya sudah berkurang dan hasilnya terdapat pada skala 4

11. Menganjurkan ibu untuk makan dan minum untuk menambah tenaga pada saat ingin mengedan.

12. Melakukan pemeriksaan 4 jam lagi menggunakan partograf.

\section{PEMBAHASAN}

\section{Data Subjektif}

Berdasarkan hasil pemeriksaan pada Ny.M pada tanggal 16 September 2020 Ibu mengatakan nyeri pinggang yang menjalar ke ari-ari. Nyeri persalinan merupakan suatu proses fisiologis yang dirasakan oleh wanita pada saat melahirkan bayi. Nyeri yang terjadi selama persalinan diakibatkan kontraksi uterus, dilatasi dan penipisan serviks, serta penurunan janin selama persalinan. Hal ini mengakibatkan naiknya tekanan darah, denyut nadi, pernapasan, keringat, diameter pupil dan ketegangan pada otot (Rahmawati \& Iswari, 2016).

Dari hasil asuhan yang telah diberikan pada ibu bahwa sesudah melakukan teknik akupressure dapat mengurangi nyeri pada ibu bersalin, karena teknik akupressure dapat meningkatkan hormon endorphin yaitu hormon yang dapat menimbulkan rasa rileks pada tubuh secara alami, memblok reseptor nyeri ke otak, dan menyebabkan dilatasi serviks (peregangan/penipisan leher rahim) serta meningkatkan efektivitas kontraksi uterus.

\section{Data Objektif}

Keadaan umum ibu baik, kesadaran composmentis, TD:120/80 $\mathrm{mmHg}$, $\mathrm{N}: 80 \mathrm{x} / \mathrm{i}, \mathrm{R}: 20 \mathrm{x} / \mathrm{I}, \mathrm{S}: 36,7^{\circ} \mathrm{C}$, hisnya $3 \mathrm{x}$ dalam 40 detik, VT $4 \mathrm{~cm}$, portio tipis lunak, ketuban (-) DJJ:140x/i. Pada pemeriksaan fisik penulis menemukan kesenjangan antara teori dengan kasus. Dimana menurut (Rositawati, 2019) partus lama dapat menyebabkan infeksi, kehabisan tenaga, dehidrasi dan perdarahan post partum yang dapat menyebabkan kematian ibu. Menurut (Syarwani et al., 2018) Ketuban pecah dini merupakan salah satu penyebab prematuritas dengan insidensi $30-40 \%$. Fackor resikonya terjadinya ketuban pecah dini yaitu usia ibu hamil, pekerjaan, paritas, riwayat KPD.

Dari hasil yang telah diberikan selama melakukan pijat akupressure. Teknik akupressure ini dilakukan 2 kali dalam pembukaan serviks pada pembukaan 4 
dan $8 \mathrm{~cm}$ dengan menggunakan titik Sp6 dan Li4 untuk mengurangi nyeri dan merangsang kontraksi, setelah itu mengukur nyeri menggunakan skala wajah atau FRS. Sebelum melakukan teknik akupressure ibu menyatakan berada dalam skala 1-5 memiliki nyeri sedang, setelah melakukan teknik akupressure bahwa hasil yang didapatkan cukup baik dapat mengurangi nyeri di pembukaan $4 \mathrm{~cm}$ menjadi turun skala 3 . Sedangkan di pembukaan $8 \mathrm{~cm}$ ibu berada dalam skala 8 yang merupakan nyeri berat berkurang menjadi skala 7 , karena di pembukaan $8 \mathrm{~cm}$ nyeri semakin kuat untuk memasuki pembukaan lengkap.

\section{Assesment}

G3P2A0 usia kehamilan 38 minggu inpartu kala 1 fase aktif dengan KPD k/u ibu baik, janin hidup, tunggal, intrauterine, presentasi kepala, $\mathrm{k} / \mathrm{u}$ janin baik.

\section{Plan}

Memberikan asuhan pada Ny.M berdasarkan keluhan pasien dan cara melakukan teknik Sp6 dan Li4 untuk mengurangi nyeri pada persalinan. Sebagaimana di dalam teori (R. Reni \& S. Sunarsih, 2017) Induksi persalinan adalah suatu tindakan untuk merangsang timbulnya kontraksi rahim sehingga terjadi persalinan. Dalam standar asuhan pelayanan kebidanan indikator komplikasi persalinan yaitu perdarahan, partus macet, kelainan presentasi, eklamsia kelelahan ibu, gawat janin, infeksi, ketuban pecah dini tanpa infeksi. Akupresur menggunakan tangan untuk memijat bagian-bagian tubuh tertentu. Titik-titik yang berhubungan dengan persalinan adalah SP6 dan LI4. Akupresur pada titik ini untuk merangsang kontraksi Rahim dan meningkatkan proses persalinan atau mengurangi nyeri persalinan (Rahmawati \& Iswari, 2016).

Menurut penulis bahwa teknik akupressure dapat mengurangi rasa nyeri pada ibu bersalin. Karna teknik ini terdapat hormon endhorphin karena bisa membuat ibu merasa rileks dan nyaman pada saat di pijat dan dapat merangsang kontraksi rahim.

\section{KESIMPULAN}

Dari data yang telah dikumpulkan, saat penulis mendapat persetujuan pasien bahwa akan dilakukan teknik acupressure, teknik ini dapat mengurangi nyeri pada persalinan kala 1 fase aktif dengan skala 1-5dengan nyeri sedang. Setelah dilakukan teknik akupressure di dapatkan hasil bahwa di pembukaan $4 \mathrm{~cm}$ ibu berada di skala 3. Sedangkan di pembukaan $8 \mathrm{~cm}$ dapat dilihat ibu berada 
skala 8 , dan hasilnya turun berada dalam skala 7. Jadi dapat disimpulkan adanya pengurangan nyeri dari asuhan pemberian teknik akupressure Sp6 dan Li4 pada ibu bersalin.

\section{SARAN}

\section{Bagi STIKes Hang Tuah Pekanbaru}

1. Agar menerapkan asuhan kebidanan dalam memecahkan masalah dapat lebih ditingkatkan dan dikembangkan mengingat metode ini sangat bermanfaat dalam membina tenaga bidan guna menciptakan sumber daya manusia yang lebih professional.

2. Perlu adanya persamaan presepsi antara pendidik dan petugas kesehatan dilahan praktek tentang penerapan asuhan kebidanan sebagai alat dalam pendekatan pencegahan masalah pada praktek sehari-hari sehingga meningkatkan mutu pelayanan tenaga kesehatan.

\section{Bagi Klinik Pratama Ar-rabih}

a. Diharapkan kepada penyedia layanan kesehatan yang sedang menjalankan praktik untuk bisa menyediakan pijat akupressure.

b. Diharapkan klinik terhadap pelayanan pada ibu bersalin dapat menyediakan leaflet untuk pijat akupressure.

\section{DAFTAR PUSTAKA}

Astuti, D. puji, \& Dewi, adinda putri sari. (2018). Nyeri Persalinan dengan Pijat Akupressure.

Ariyanti, R., \& Aulia. (2019).

PENGARUH TERAPI

AKUPRESUR PADA TANGAN

TERHADAP NYERI

PERSALINAN KALA I FASE

AKTIF. Jurnal Kebidanan Mutiara

Mahakam.

Damayanti, P., I., Maita, L., Triana, A., \& Afni, R. (2014). Buku Ajar

Asuhan Kebidanan

Komprehensif Pada Ibu Bersalin dan Bayi Baru Lahir. Yogyakarta:

CV Budi Utama.

Fitriana, Y., \& Nurwiandani, W. (2018). Asuhan Persalinan Konsep

Persalinan Secara Komprehensif

dalam Asuhan Kebidanan. Pustaka Baru Press.

Fauziah, S. (2015). Keperawatan

Maternitas volume 2: Persalinan.

Hidayat, A., \& Sujiatini. (2010). Asuhan Kebidanan Persalinan. Nuha

Medika. 